\title{
"La furia de buscar el oro". Los asientos mineros del siglo XVIII y XIX en la Puna de Jujuy, Argentina
}

\author{
( Carlos I. Angiorama" \\ Marco Giusta "* \\ María Florencia Becerra**** \\ María Josefina Pérez Pieroni ${ }^{* * * * *}$
}

Fecha de recepción: 30 de noviembre de 2017. Fecha de aceptación: 30 de mayo de 2018

Palabras clave

Puna de Jujuy minería aurífera pueblos mineros siglos XVIII y XIX

\section{Resumen}

Durante el período colonial y el republicano en la Puna de Jujuy se desarrollaron numerosos emprendimientos mineros, cuya consecuencia fue la proliferación de asientos dedicados a la minería del oro y la plata. Aquí presentamos y comparamos las características de tres poblados, emplazados en una pequeña porción del paisaje puneño, que crecieron en torno a la minería aurífera; también indagamos sobre las diversas trayectorias históricas que desembocaron en la variabilidad observada en las evidencias arqueológicas que perduran en cada uno. A un estudio netamente arqueológico que involucra, entre otros aspectos, análisis de la espacialidad de los asentamientos, de las características arquitectónicas de las estructuras y de los artefactos y los rasgos que aún hoy se conservan, hemos sumado registros escritos de diversa índole, tanto de esta región como de áreas análogas, donde se encuentra documentación colonial, relatos de viajeros, informes geológicos, informes oficiales y catálogos de materiales coloniales.

\section{"La furia de buscar el oro". Mining settlements in Puna of Jujuy, Argentina.18th and 19th centuries}

\section{Abstract}

Key words

Puna of Jujuy gold mining mining towns $18^{\text {th }}$ and $19^{\text {th }}$ centuries
During the colonial and republican periods, many mining undertakings were developed in the Puna of Jujuy leading to the proliferation of settlements

"Instituto de Arqueología y Museo, Facultad de Ciencias Naturales e Instituto Miguel Lillo, Universidad Nacional de Tucumán - Instituto Superior de Estudios Sociales, Consejo Nacional de Investigaciones Científicas y Técnicas. San Miguel de Tucumán, Tucumán, Argentina. E-mail: carlosangiorama@gmail.com

** Instituto de Arqueología y Museo, Facultad de Ciencias Naturales e Instituto Miguel Lillo, Universidad Nacional de Tucumán - Instituto Superior de Estudios Sociales, Consejo Nacional de Investigaciones Científicas y Técnicas. San Miguel de Tucumán, Tucumán, Argentina E-mail: giustamarco@yahoo.com.ar

**t* Instituto de Arqueología, Facultad de Filosofía y Letras, Universidad de Buenos Aires - Consejo Nacional de Investigaciones Científicas y Técnicas. Buenos Aires, Argentina. E-mail: florenciabecerra@gmail.com

Instituto de Arqueología y Museo, Facultad de Ciencias Naturales e Instituto Miguel Lillo, Universidad Nacional de Tucumán - Instituto Superior de Estudios Sociales, Consejo Nacional de Investigaciones Científicas y Técnicas. San Miguel de Tucumán, Tucumán, Argentina. E-mail: josefinaperezp@gmail.com 
dedicated to gold and silver extraction. The characteristics of three settlements, placed in a small portion of the Puna landscape, which developed around gold mining are presented and compared in this paper; their different historical trajectories are also studied since a degree of variability in the archaeological evidence was observed in each case. Thus to a purely archaeological study, including spatiality, preserved architectonic structures, artifacts and features analysis, we have added a diversity of written records from this and similar areas such as colonial documents, travel journals, geological and official reports, and catalogues of colonial material.

\section{Introducción}

El análisis del proceso de ocupación de la Puna de Jujuy (Argentina) a lo largo del período colonial nos indica una vinculación estrecha entre los "descubrimientos" y los vaivenes de la producción minera, con las fundaciones de nuevos poblados en la región y la cesión de mercedes de tierras (cf. Gil Montero, 2004; Sica, 2006; Albeck y Palomeque, 2009). Hasta el momento parece claro que durante las tres primeras décadas del siglo XVII, el sur de la Cuenca de Pozuelos y la sierra de Carahuasi-Rinconada constituían el centro de atracción para aquellos que deseaban probar suerte con la actividad minera regional. Ese sector de la puna jujeña incluía las llamadas minas de Cochinoca y las explotaciones auríferas localizadas en las inmediaciones de Santiago de la Rinconada del Oro, de Nuestra Señora de la Guadalupe y de Ajedrez. Como bien lo señalaron Sica (2006) y Albeck y Palomeque (2009) no es casual que sea en ese sector donde se concentraron, a su vez, las primeras mercedes de tierra concedidas en la Puna de Jujuy entre los años 1594 y 1636, cuyos beneficiarios se vincularon de un modo u otro con la explotación minera (Sica, 2006; Albeck y Palomeque, 2009; Estruch et al., 2011; Becerra, 2012; Estruch, 2013).

Más allá de sus altibajos, la minería continuó teniendo aún en el siglo XVIII un rol predominante en la organización del espacio y la población atrayendo nuevos habitantes, mineros o comerciantes, y permitiendo consolidar así a los poblados fundados inicialmente. Las expectativas sobre el asiento de Rinconada, de quien fue propietario de la hacienda homónima durante parte de este período, consistían en que "creciera el pueblo como Potosí", dando para ello "sitios para trabajar casas en este pueblo a todos quienes lo pedían". ${ }^{1}$ Aunque nunca llegó a igualar a ese gran centro minero, en Rinconada residían "no sólo sus indios naturales sino también muchos españoles mestizos, que con motivo de las minas y rescates de oro vienen a ellos y ponen sus pulperías". ${ }^{2}$ De este modo, se convirtió en un importante centro mercantil en el que se habían instalado 44 pulperías entre 1784 y 1791. Santa Catalina, por su parte, en ese entonces contaba con 15 establecimientos del mismo tipo (Sica y Ulloa, 2007).

Durante el siglo XVIII se concretaron nuevos asientos en la región, como Antiguyoc y Santo Domingo. Estos últimos llegaron a reunir tal cantidad de población que fueron designados posteriormente como sedes de Viceparroquia (Gil Montero, 2004). En cambio, otros yacimientos en explotación se habrían conformado como pequeños caseríos de "forasteros sin tierras", como San Francisco o Timón Cruz, en la doctrina de Santa Catalina. ${ }^{3}$

En esta oportunidad nos referiremos específicamente a los poblados de Ajedrez y Antiguyoc, y a un asentamiento registrado en una quebrada colindante al que hemos llamado Quebrada del Maray 4, todos localizados en la ladera occidental de la Sierra de Carahuasi (Departamento de Rinconada, Jujuy). Nos
1. AGN. Sala IX, Leg. 34-4-6, f. 8. Año 1803 (Becerra, 2014a).

2. AGN, Sala IX, Leg. 33-8-5, en Gil Montero (2004: 110).

3. AGN, Sala XIII, 17-2-1, fs. 127V.-128. 
4. ATJ. Carpeta 26, Leg. 794, f. 1. Año 1706. En el marco del pleito por la posesión de tierras se transcribe la mencionada merced concedida a Pedro de Olmos y Aguilera de las tierras de El Pucará, firmada en 1627. Sin embargo, quien firma esta merced es el gobernador Francisco de Avendaño y Valdivieso, quien habría iniciado sus actividades en el cargo recién en 1637. Al tratarse de un traslado de la merced, realizado en 1706 es probable que se trate de un error en la transcripción. De todos modos, para el caso que nos ocupa, sea 1627 o 1637, la mención al mineral de Ajedrez resulta significativamente temprana.

5. ABHS, Colección del Marquesado del Valle de Tojo (CMVT), f. 21. Año 1738.

6. ACRR, Caja XVIII. Citado por Gil Montero (2004).

7. ABHS, Documentaciones Varias, Registro Minero, Carp. 63, Cuad. 94. Año 1825. Agradecemos a Cecilia Castellanos el habernos buscado y fotografiado este documento en el Archivo, referido por Alonso (2010).

8. Además de la licencia de Dabalos, se especifica la "don Nazareno Bejarano en Ajedrez en venero de opinión" (3v.). Por otra parte, hay un listado de licencias que han sido concedidas pero que no han sido "posesionadas por no haberlas pedido hasta la fecha". En ellas se incluye una en Ajedrez a don Domingo Saravia en venero, y una estaca para cada uno de sus cuatros hijos menores; a cada uno de los siete hijos de Francisco de la Cuesta en la quebrada de Ajedrez, contiguas a las de Saravia (f. 3v.), a don Gaspar Castellanos, otra contigua a Dabalos y una más para catear, y también a don Marcos Estupiñan.

9. Cabanettes y Amans (1891: 36) en su expedición recorren toda la quebrada de Ayedrez (Ajedrez) que "no forma sino una sola pertenencia minera, de la compañía La Aurífera Jujeña, constituida por la casa de Torres hermanos de Buenos Aires, que desde unos cinco años ha gastado allí un dineral en trabajos de cateo, reconocimientos y construcciones".

10. Continúa la cita: “á mas de los veneros y placeres que allí abundan, existen también vetas importantes de cuarzo aurífero que quedan vírgenes todavía. Todas esas pertenencias son de la Auríferas Jujeña, que ha construido allí algunos trabajos de cateo y de reconocimiento en vista de los lavaderos que piensa establecer más tarde en esos puntos" (Cabanettes y Amans, 1891: 45). proponemos comparar las características de estos tres sitios emplazados en una pequeña porción del paisaje minero puneño, tratando de indagar acerca de las diversas trayectorias históricas que desembocaron en la variabilidad que hoy observamos en las evidencias arqueológicas que perduran en cada uno de ellos. A un estudio netamente arqueológico que involucra, entre otros aspectos, el análisis de la espacialidad de los asentamientos, de las características arquitectónicas de las estructuras preservadas, y de los artefactos y rasgos que aún hoy se conservan en ellos, hemos sumado la consulta de diversos registros escritos, tanto de esta región como de áreas análogas, tales como documentación colonial, relatos de viajeros, informes geológicos, informes oficiales y catálogos de materiales coloniales.

\section{Información histórica sobre los sitios investigados}

Ajedrez aparece tempranamente en la documentación histórica vinculada a deslindes de tierras. En un pleito desatado en 1706 se realiza la transcripción de una merced de tierras fechada en 1627 -pero probablemente efectuada en 1637- donde uno de los puntos de referencia para establecer límites es el "mineral del Ajedrez". ${ }^{4}$ En documentación de 1738 lo encontramos ya como "mineral de oro del Ajedrez" ${ }^{5}$ (Becerra, 2014a). No hallamos más referencias específicas a la explotación de este yacimiento ni al asiento para momentos coloniales, aunque en el siglo XVIII habría tenido todavía un rol protagónico en el escenario de la minería puneña, ya que para 1772 Ajedrez es mencionado como uno de los anejos del curato de Cochinoca, junto con Rinconada, Río de San Juan y Casabindo. ${ }^{6}$ Volvemos a encontrar mención a él ya en época republicana, en un registro de licencias para explotar minas de oro y plata de 1825, donde se relata que "solo don Cecilio Dabalos /descubridor/ está dando socavón a la suya [la mina] en Ajedrez con doscientos mil trabajos, muchas veces falto de recursos". ${ }^{7}$ En este registro se mencionan otras licencias allí, una ya posesionada y otras nuevas. ${ }^{8}$ En 1883 Brackebusch llega hasta el mineral de Ajedrez señalando que "en la extensión de una legua sigue una casa a otra, una mina vieja a otra mina vieja" (Brackebusch, [1883] 1981: 44). Otros geólogos que pasaron por la zona también dieron cuenta de las evidencias de las explotaciones antiguas (Novarese, 1893: 110). Desconocemos el éxito o la duración que tuvieron los emprendimientos iniciados en 1825 pero sabemos que hacia finales del siglo XIX se retomaron los trabajos; esta vez con una empresa a mayor escala, según se desprende de las descripciones aportadas por Cabanettes y Amans (1891), y Torre (1906, citado en Alonso et al., 2013). En aquella oportunidad los trabajos estuvieron a cargo de la compañía "Aurífera Jujeña", de los hermanos Torre, y para llevarlos adelante se habrían construido "dos casas para oficinas, laboratorios químicos, un gabinete geodésico, habitaciones del personal técnico y administrativo, más de 80 viviendas para habitaciones de los obreros" (Alonso et al., 2013: 162). ${ }^{9}$ Cabanettes y Amans dicen que toda la cuesta "está enteramente agujereada por piques y socavones" (1891: 43). Además mencionan otros tres sitios que visitaron en el área: "los antiguos lavaderos de Antiguyo, Rancho de Ayedrez y Maray". ${ }^{10}$

Para comienzos del siglo XX, Sgrosso (1943) señala que compañías inglesas llevaron a cabo explotaciones de oro que implicaron el traslado al lugar de dragas y máquinas pesadas. Finalmente, un nuevo proyecto de extracción aurífera en la zona fue aprobado en 2015, aunque no nos consta aún su inicio efectivo.

Hasta 1772 el territorio de la puna jujeña estaba dividido en dos curatos: Santa Catalina y Cochinoca. Este último contaba con los anexos de Rinconada, 
Casabindo, Río de San Juan y Ajedrez (ACRR, Caja XXVIII, citado por Gil Montero, 2004). Cuando un año después quedó conformado oficialmente el curato de Rinconada, Antiguyoc pasó a constituir una de sus viceparroquias (Vergara, 1942). Es decir que en 1773 la zona en la que se encuentran los sitios que estudiamos en este trabajo fue "cubierta" con la Viceparroquia de Antiguyoc, en lugar de conservar a Ajedrez. Pensamos que esta modificación o reemplazo pudo haber respondido a un abandono -al menos parcial- de la ocupación en Ajedrez, quizás motivada por un menor rendimiento en la extracción de mineral, y al inicio de explotaciones en otras áreas cercanas, como en la quebrada donde se emplazó Antiguyoc, que junto a la hacienda de Rinconada y Santa Catalina estaban estrechamente vinculadas a las actividades mineras (Gil Montero, 2004). De hecho la de Antiguyoc, al menos bajo la propiedad del empresario minero y hacendado Fernando Dávalos, sabemos -con seguridad- que se encontraba abocada a la extracción de minerales y a la ganadería, entre otras actividades (Ulloa, 2005). Allí habría estado ubicada su vivienda, la de su esclava, una tienda, depósitos de herramientas y una cancha de matanza de ganado, las cuales fueron descriptas con cierto detalle en un inventario de sus bienes poco antes de morir, hacia finales de 1776. De acuerdo con este documento, Dávalos poseía ganado en varios parajes de la región y tenía adjudicadas nueve estacas de minas de oro, de las cuales cuatro estaban en trabajo efectivo en esa fecha. ${ }^{11}$ Este inventario permite conocer también, al menos en parte, a los trabajadores de esta hacienda. Ulloa (2005) destacó que Dávalos empleaba indígenas de la encomienda de Casabindo y Cochinoca para las labores extractivas llevadas adelante en ese asiento. De todas maneras, es posible que la mano de obra principal haya provenido de los "forasteros sin tierra" residentes en la zona, tal como se desprende del censo de 1778/79 (Rojas, 1913) y del padrón de $1786 .{ }^{12}$

La actividad ganadera y minera registrada para este poblado, junto a su designación como anejo del curato de Rinconada, contrasta con una ausencia en los documentos de aquella época de menciones sobre Ajedrez. Mientras que Antiguyoc figura en el censo levantado en $1778 / 79$ y en los padrones de 1786 y 1806 no ocurre lo mismo con Ajedrez, lo que refuerza la hipótesis de un posible abandono del asiento o al menos la pérdida de importancia del mismo más allá de los pedidos de licencia fechados en 1825.

A pesar de la relativa importancia del asiento de Antiguyoc, no contamos con demasiadas referencias sobre éste, sus pobladores y su vida cotidiana. En el censo realizado en el año 1778/79 se menciona el "partido de Antiguio", enumerando 287 personas entre las cuales se encontraba la familia de Dávalos, una mujer negra que había sido su esclava, dos hombres españoles, algunos mestizos y población indígena (Rojas, 1913).

Gil Montero (2004) ha analizado documentación en la que se relatan hechos ocurridos en este paraje; como por ejemplo el juicio por la muerte de un indio llamado Pablo Cayo en 1780. De allí se desprenden detalles que de alguna forma caracterizan al poblado en su doble condición de Viceparroquia y asiento de mineral, como la mención a la parroquia y al cura y la existencia de "labores de mina" (Gil Montero, 2004). Luego de la muerte de Dávalos, las tierras de Antiguyoc habrían quedado en manos de un vecino de la ciudad de Jujuy, Don Francisco Antonio de Azebey. ${ }^{13}$

Sabemos además que los españoles habían tejido redes que incluían distintos asientos de la Puna, y que Antiguyoc estaba incorporado a ellas. ${ }^{14}$ La minería brindó un escenario propicio para una variedad de negocios en los que el oro
11. ATJ, Carpeta 5o, Leg. 1653 , fs. 9 -10v. Año 1776.

12. AGN, Sala XIII, Leg. 17-2-1.

13. AGN, Sala IX, Leg. 23-5-6, Exp. 310. Año 1803.

14. Al respecto, sabemos que en 1777 Tadeo Picolomini debía 220 pesos, a cuenta de lo cual entregó a su acreedor 12 onzas de oro en la doctrina de San Joseph de la Rinconada, mientras que de otra deuda canceló 4 onzas de oro a su hermano en el mineral de Antiguyoc. Además, poseía mulas en el potrero de invernada en el río de San Juan (AT), Carpeta 51, Leg. 1680. Año 1777). Además el mencionado Dávalos tenía una prima en Potosí a la que le mandaba sebo, charque, grasa, vejigas, entre otros productos, y ella le enviaba monturas, zapatos, dulces, entre otras cosas. También tenía vinculación con la hacienda de su suegro en Tupiza, con el marqués de Yavi, y con personas de Rinconada, entre otros. 
15. AGN, Sala IX, 30-5-2, Exp. 31, Leg. 35, fs. 8-8v. Año 1792; Becerra (2014b). o la plata extraídos se transferían rápidamente y de manera informal a terceros que se encontraban lejos de la dura práctica extractiva o de beneficio. En este contexto se entiende que en el siglo XVIII, refiriéndose a las doctrinas de Rinconada y Santa Catalina, se planteara desde la Intendencia de Salta que éstas eran:

[...] de las más pobladas de todas las de la campaña de la provincia pero de indios tributarios, foráneos, originarios, y yanaconas con minerales de oro y plata en cuyo rescate emplean continuamente españoles, comerciantes llevando licores, coca y otros efectos de castilla y de la tierra con que hacen un continuado giro de comercio bien lucrativo. ${ }^{15}$

Por último, a mediados del siglo XX Jutoran (1958) realiza un informe sobre las manifestaciones auríferas de los departamentos de Cochinoca y Rinconada. Allí describe un poblado hispánico abandonado en las adyacencias de la quebrada que delimita los departamentos de Cochinoca y Rinconada. Señala tres grupos de construcciones, uno con patio y habitaciones amplias, otro sin patio y finalmente en el centro, el núcleo de la iglesia y sus edificaciones próximas. También distingue hornos para pan, corrales, y áreas con evidencias de lavado de oro. Aunque no menciona el nombre del poblado que describe sus referencias nos hacen pensar que se habría tratado de Antiguyoc.

\section{El análisis de los sitios desde la arqueología}

Como hemos mencionado, Ajedrez, Antiguyoc y Quebrada del Maray 4 se encuentran emplazados en la ladera occidental de la Sierra de Carahuasi. Ajedrez y Antiguyoc se ubican a una distancia entre sí de $5 \mathrm{~km}$ en línea recta, mientras que Antiguyoc y Quebrada del Maray 4 distan $2 \mathrm{~km}$ en línea recta uno del otro. Por lo tanto, una distancia de $7 \mathrm{~km}$ lineales vincula a los tres sitios (Figuras 1 y 2).

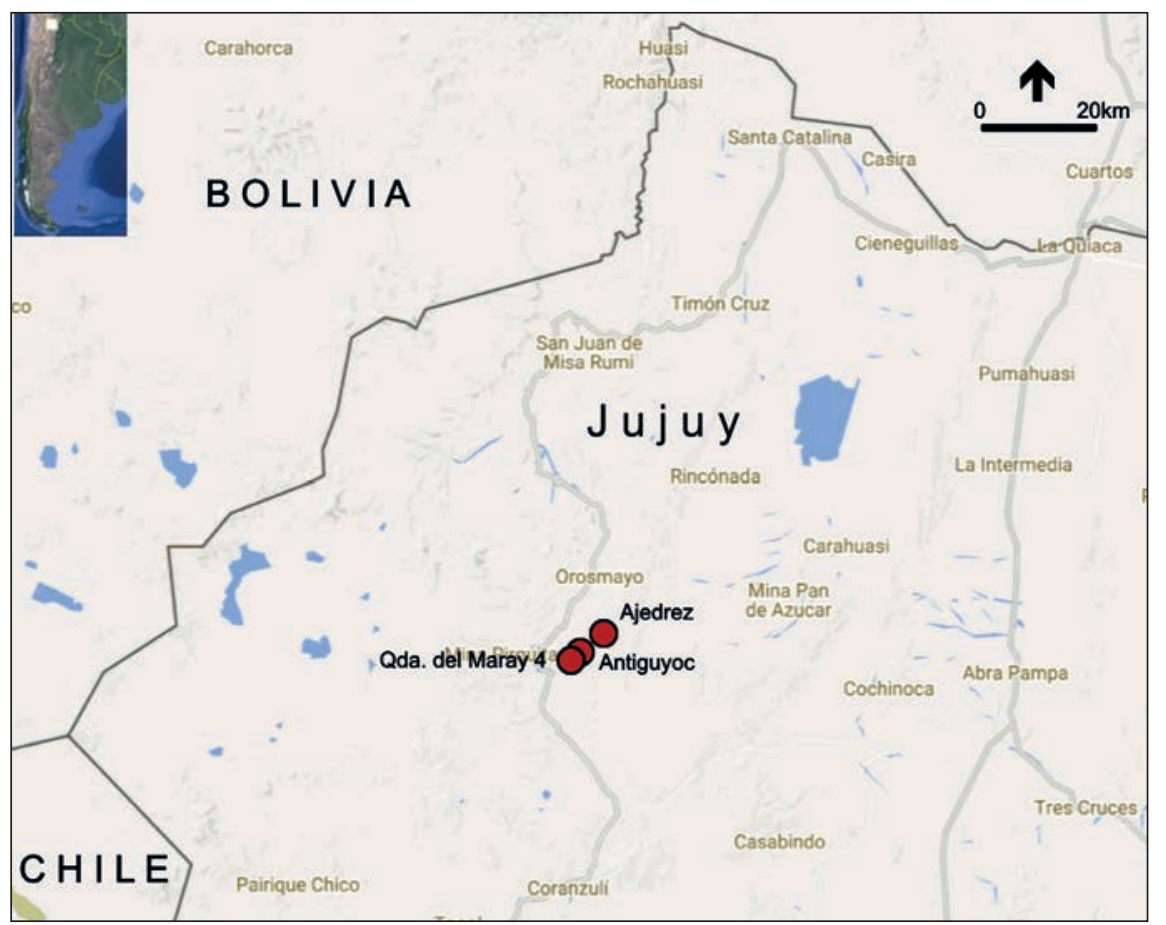

Figura 1. Mapa con ubicación de los sitios en la región. 

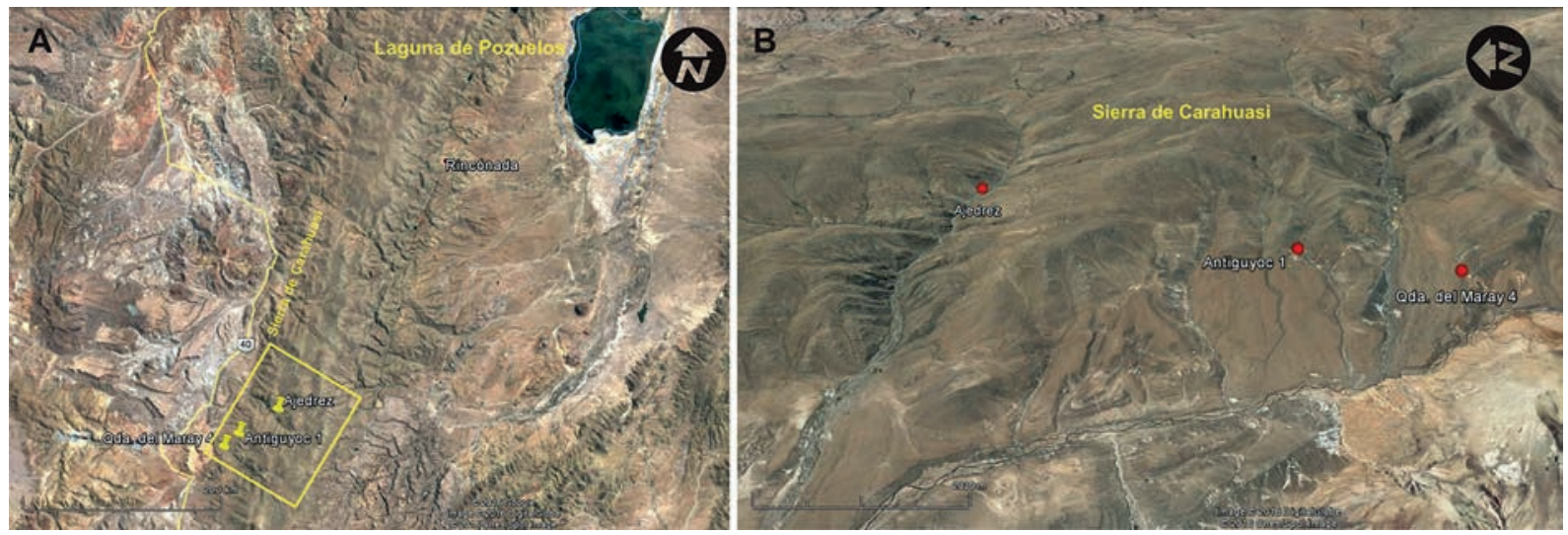

Figura 2. A. Ubicación de los sitios en el área de estudio. B. Ampliación del recuadro en perspectiva. Imágenes modificadas de Google Earth.

El trabajo arqueológico de campo realizado en los tres sitios consistió en un relevamiento en el que se definieron grupos de estructuras asociadas -denominados Conjuntos Arquitectónicos-, seguido por un registro detallado de las características arquitectónicas y una recolección sistemática de muestras indiscriminadas de materiales arqueológicos hallados en superficie, ${ }^{16}$ los cuales fueron luego analizados en el gabinete siguiendo los protocolos habituales desarrollados por nuestro equipo.

Antiguyoc es un caserío conformado por construcciones en piedra que se disponen en un área aproximada de $360 \mathrm{~m}$ por $180 \mathrm{~m}$ (Figura $3 \mathrm{~B}$ ). El poblado posee un núcleo central en el que destacan una iglesia con su patio posterior delimitado por muros altos en "L", la torre de campanario y un espacio despejado al frente, a modo de "plaza". En este sector los conjuntos arquitectónicos se hallan más próximos entre sí, mientras que a medida que se alejan de la iglesia se encuentran algo más distanciados. El cementerio, ubicado a unos $200 \mathrm{~m}$ de la iglesia, es otra de las construcciones que predomina visualmente.
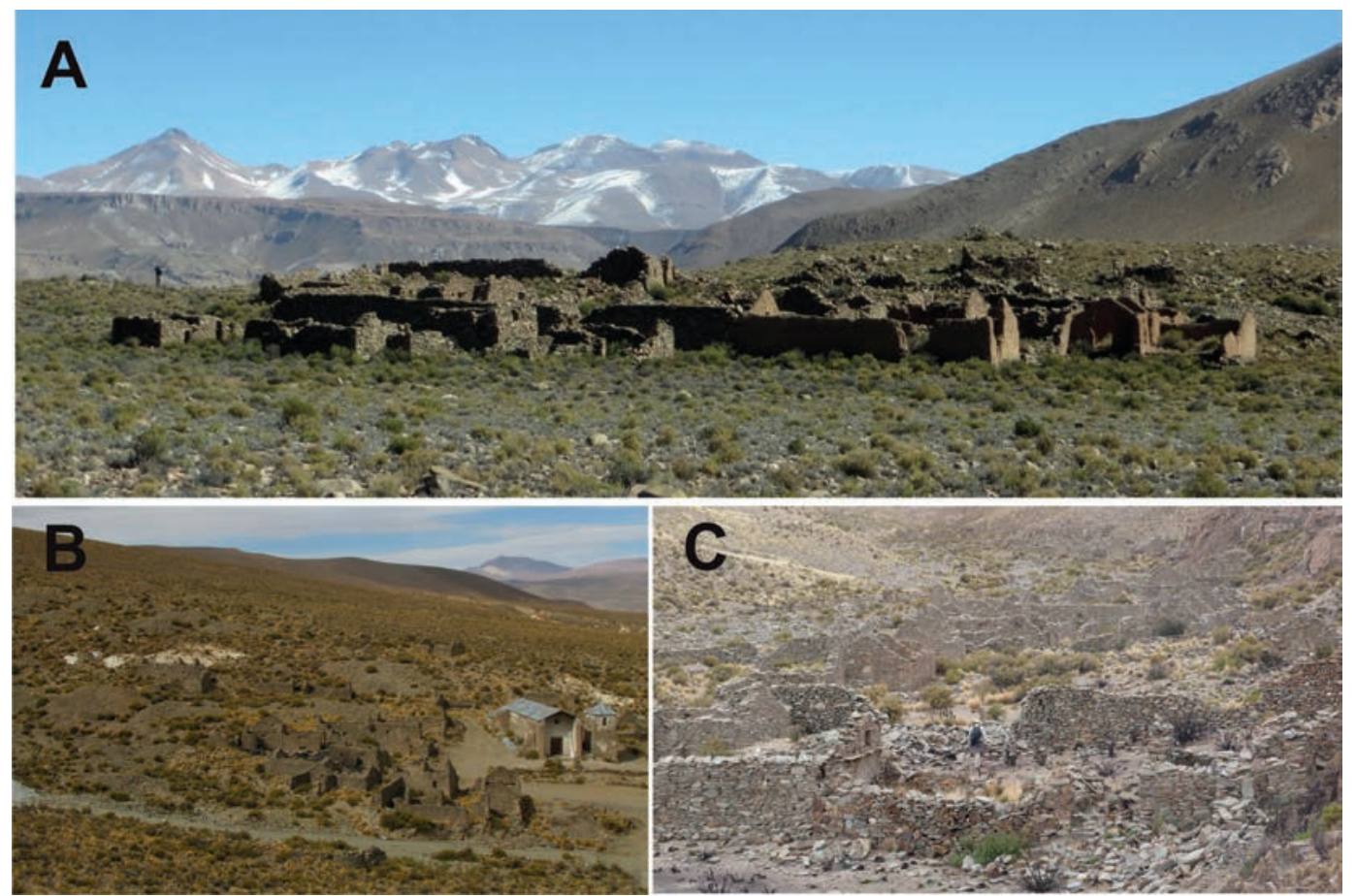

Figura 3. Vistas parciales de los sitios investigados. A. Quebrada del Maray 4. B. Antiguyoc. C. Ajedrez.

16. Exceptuando los vidrios que por ser muy abundantes se recolectaron sólo los fragmentos diagnósticos de forma y de técnicas de manufactura. 
17. Se distinguen, a grandes rasgos, dos variantes de poyos: "tipo asiento" y "tipo cama" (Schilman y Reisner, 2011). Los primeros son por lo general angostos y alargados; en el interior comúnmente están ubicados sobre los muros largos, mientras que en el exterior contra el muro de la fachada. Los segundos son más cortos y anchos y se disponen en el interior, por lo general, contra los muros más cortos.
Por lo general, los conjuntos arquitectónicos se disponen espacialmente siguiendo uno de entre dos patrones distintos: alrededor de un patio o de forma alineada. Las estructuras que habrían sido utilizadas como vivienda presentan un diseño de planta rectangular o cuadrangular con hastiales para techo a dos aguas ( $\mathrm{n}=52$, Tabla 1$)$. En su mayoría contienen rasgos arquitectónicos elaborados con piedra que consisten en nichos, poyos, ${ }^{17}$ estantes y muros tipo "mesa". En algunos casos presentan adosados recintos menores de morfología diversa, levantados con muros bajos sin hastiales. Además, algunas de las agrupaciones de viviendas contaban con un horno, del cual en algunos casos solo se conserva su base de piedra.

\begin{tabular}{|c|c|c|c|c|c|c|}
\hline & \multicolumn{2}{|c|}{ Ajedrez } & \multicolumn{2}{c|}{ Antiguyoc } & \multicolumn{2}{c|}{ Quebrada del Maray 4 } \\
\cline { 2 - 7 } & $\mathrm{n}$ & $\%$ & $\mathrm{n}$ & $\%$ & $\mathrm{n}$ & $\%$ \\
\hline $\begin{array}{c}\text { Estructuras con techo } \\
\text { a dos aguas }\end{array}$ & 164 & 84,5 & 52 & 100 & 29 & 85,3 \\
\hline $\begin{array}{c}\text { Refugios con techo } \\
\text { en falsa bóveda }\end{array}$ & 24 & 12,4 & 0 & 0 & 5 & 14,7 \\
\hline Refugios excavados & 6 & 3,1 & 0 & 0 & 0 & 0 \\
\hline Total & 194 & 100 & 52 & 100 & 34 & 100 \\
\hline
\end{tabular}

Tabla 1. Estructuras techadas en los sitios estudiados.

Existen también construcciones en piedra de muros bajos y variada morfología que habrían sido utilizadas como corrales. Algunas de ellas se encuentran próximas a espacios de vivienda, aunque distanciadas del núcleo central del poblado en el que se ubica la iglesia.

Las evidencias de explotación minera -piques, socavones y trincheras para lavado de oro- se ubican en diversos sectores del poblado y a lo largo de la quebrada en la que está emplazado.

Se observan también numerosas evidencias de reocupaciones esporádicas, de duraciones y propósitos variados. Éstas se vinculan en la actualidad a fechas y festividades religiosas, donde la iglesia y el cementerio son espacios habitualmente visitados. En el cementerio, que se encuentra en la entrada actual del poblado, las fechas más antiguas que se observan en las tumbas corresponden a las primeras décadas del siglo XX -alrededor de 1930-, contemporáneas al comienzo de la explotación de estaño y plata en la cercana Mina Pirquitas. La iglesia, por otro lado, exhibe claros signos de remodelaciones actuales o subactuales. A su vez, durante nuestros trabajos de campo hemos constatado la concurrencia de personas en días como el 7 de octubre (Virgen del Rosario) y 2 de noviembre (Fieles Difuntos). Esto implicó en algunos casos la modificación de algunos sectores del lugar. Por ejemplo, en 2016 dos de los recintos habitacionales fueron techados con chapa y se instaló luz eléctrica para la breve estadía de los visitantes.

Quebrada del Maray 4 (Figura 3 A) es un sitio que cuenta con dos sectores diferenciados claramente entre sí por la disposición espacial de sus construcciones. El primero de ellos consiste en un polígono irregular de límites definidos, conformado en su interior por dieciocho unidades arquitectónicas y siete patios de variadas dimensiones. Los muros de algunos de los recintos y de los dos patios más amplios funcionan como elementos que circunscriben esta área de $75 \times 55 \mathrm{~m}$ aproximadamente. Hacia el interior de este espacio, algunas de las estructuras están orientadas hacia los dos patios mayores, mientras que otras 
se disponen alrededor de patios de dimensiones menores. Complementan este sector principal seis recintos que se ubican hacia el este, por fuera del núcleo descripto, pero a una proximidad tal que permite intuir cierta vinculación funcional.

En su mayoría las construcciones presentan planta rectangular y predomina la edificación en piedra. Las estructuras con técnica mixta -levantadas en adobe con sobrecimientos de piedra- son minoritarias pero poseen mayores dimensiones y en ellas se observan modos de vinculación entre recintos que están ausentes en las construcciones en piedra; como por ejemplo una unidad arquitectónica con cuatro recintos conectados a través de vanos -tres alineados y uno perpendicular hacia atrás, conformando una L. Ambos tipos presentan hastiales en los muros más cortos, por lo que habrían estado techadas a dos aguas aunque también se registraron en menor proporción estructuras de muros más bajos y sin hastiales. En su interior, los recintos contienen elementos como poyos, estantes, muros tipo "mesa" y nichos. Dentro de este núcleo destaca el patio central, de 50 y 45 m en sus lados más largos, el cual presenta muros perimetrales de hasta $3 \mathrm{~m}$ de altura, un ingreso muy bien definido en uno de sus lados y una estructura circular de piedra en el vértice sureste, cuyo interior contiene abundantes restos óseos de fauna. Hemos registrado espacios con similares características en otras localidades de la Puna de Jujuy, como Rinconada y Yoscaba, que invitan a pensar en lugares destinados a la matanza de ganado.

El segundo sector identificado en este sitio consiste en 39 recintos ubicados en el exterior del conjunto descripto anteriormente. Se disponen espaciados y de manera alineada en sentido sureste-noroeste, a lo largo de casi 600 metros. Un tramo de esta alineación transcurre por el lado oeste del núcleo central. Actualmente puede distinguirse una senda asociada a estas estructuras que, en la mayor parte de su extensión, pasa por el frente de los recintos. Las construcciones con hastiales para techo a dos aguas presentan planta cuadrangular y muros de piedra, en algunos casos acompañados por recintos adosados de menores dimensiones y muros bajos -los cuales no habrían estado techados. A pesar del derrumbe que sufrieron los muros de muchos de los recintos, hemos registrado en este sector algunos techados mediante "falsa bóveda" (Angiorama y Becerra, 2012). Las asociaciones entre los distintos tipos nunca superan aquí los tres recintos. La mayor parte de estas estructuras se encuentra vinculada espacialmente a sectores con evidencias de laboreos mineros -pozos, desmontes y plataformas. También se registraron desmontes en gran densidad en una pequeña quebrada adyacente al sitio.

Ajedrez es un poblado conformado por una serie de estructuras edificadas en una quebrada angosta (Figura $3 \mathrm{C}$ ). Los recintos ocupan las estrechas terrazas que de manera discontinua se extienden junto al río, a lo largo de un tramo de 3,6 km de largo. Las mayores concentraciones edilicias se encuentran en las tres terrazas centrales de este corredor natural haciéndose las estructuras más esporádicas, tanto aguas arriba como aguas abajo. En una porción de $570 \mathrm{~m}$ de largo de este sector central se registraron más de un centenar de estructuras, de las cuales 93 poseen hastiales para techado a dos aguas. Si consideramos la totalidad del sitio, la cantidad de estructuras edificadas -tomando como medida comparativa únicamente los espacios que con seguridad estuvieron techados- es más de tres veces mayor que la de Antiguyoc (Tabla 1). Al igual que en el caso de Antiguyoc, pasillos estrechos permiten la circulación entre las viviendas en los sectores más densamente edificados. Un camino formatizado de aproximadamente $1,5 \mathrm{~m}$ de ancho recorre la quebrada atravesando 
los diversos sectores, prolongándose más allá de las últimas construcciones del poblado.

En Ajedrez, al igual que en los casos anteriores, predomina la arquitectura en piedra. Sin embargo, se observan también algunas estructuras edificadas con adobe o con una combinación de adobe y piedra. Las plantas de los recintos habitacionales son predominantemente de forma rectangular, con techo a dos aguas. En su interior se hallan los mismos tipos de elementos que en Antiguyoc y Quebrada del Maray 4; es decir, poyos, estantes, nichos, y muros tipo "mesa". Tal como ocurre en aquellos sitios, es frecuente la presencia de hornos para pan en los conjuntos constructivos. Algunas de las estructuras residenciales se encuentran asociadas a corrales, sobre todo las emplazadas en los extremos del poblado. Un tipo de refugio presente en Ajedrez, no registrado hasta ahora en los otros dos sitios, consiste en una habitación excavada bajo tierra a partir de las barrancas del río, con una pequeña abertura para el ingreso, a veces parcialmente tapiada, y rasgos domésticos en su interior -poyo, mesa, nichos. Algunos de los conglomerados del poblado presentan un espacio despejado a modo de patio.

Una de las construcciones de piedra presenta rasgos que permiten pensar que allí funcionó un oratorio o capilla. En uno de sus muros exhibe un inusual nicho cuyo límite superior fue resuelto mediante dos lajas en punta (Figura 4). Los aparejos de los muros incluyen hiladas elaboradas mediante la técnica de opus spicatum, o espina de pez, rasgo que no es frecuente ya que solo fue registrado en esta estructura y en otra adosada. En Antiguyoc también hemos registrado su presencia en muros de un único conjunto arquitectónico, próximo a la iglesia. Cabe señalar que este modo de disponer los elementos constructivos, ya sea en muros o pisos, se ha registrado en edificaciones de la Antigua Roma y se retomó en Europa alrededor del siglo X. En España se documentaron varios casos en los que la técnica se usó para decorar construcciones vinculadas a la práctica religiosa (cf. Freixas Camps, 1975; López Mullor 2010, entre otros). En la América colonial se conocen casos similares, como por ejemplo los pisos de la Catedral y el Convento de la Compañía de Jesús en Panamá La Vieja (Martín-Rincón, 2001).

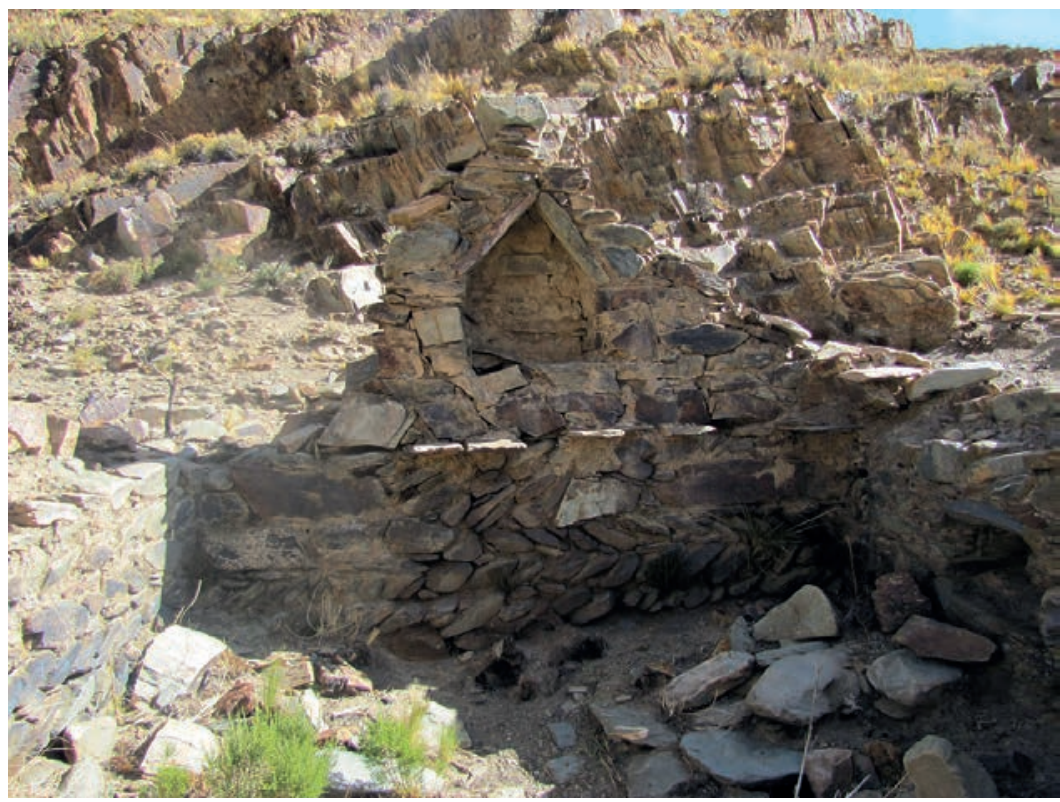

Figura 4. Construcción en Ajedrez que posiblemente funcionó como iglesia. 
Del total de estructuras relevadas también se destaca un complejo que consiste en un gran patio rectangular cercado con muros de gran porte, de unos $70 \mathrm{~m}$ de largo por $40 \mathrm{~m}$ de ancho, junto al que se ha levantado una serie de recintos rectangulares construidos en torno a otro patio central más pequeño. El acceso a este complejo se realiza atravesando vanos con arco de medio punto, algo muy poco común en estos asentamientos. A diferencia del resto del poblado, que parece haber crecido sin planificación previa, el complejo descripto responde a un plan específico y es probable que haya sido construido en un único evento.

A lo largo de la quebrada se conservan siete piques y nueve socavones antiguos, varios de ellos con la entrada formatizada con muros de rocas, con nichos y escalera de ingreso. A ellos se suman seis pozos que son el resultado de la extracción de sedimento aurífero para su lavado.

\section{Descripción de los materiales arqueológicos}

En todos los sitios analizados, los materiales más abundantes recolectados son los cerámicos, incluyendo ordinarios, con vitrificados, loza, porcelana y gres $(n=1372)$. Luego siguen los vidrios $(n=300)$, los restos óseos de fauna $(n=69)$, los objetos de metal $(n=36)$, los fragmentos de escoria $(n=30)$ y algunos objetos diversos $(n=15)$.

La gran mayoría de los materiales recuperados (79,2\%) proceden de Antiguyoc, sólo el 11,6\% proviene de Quebrada del Maray 4 y el 9,2\% de Ajedrez. Asimismo, en Antiguyoc están presentes todas las categorías de materiales identificadas, mientras que en Quebrada del Maray 4 no se han hallado fragmentos de loza, ni de porcelana, ni de botellas de vidrio. En Ajedrez, por su parte, no se han hallado fragmentos de vidrio que no correspondan a botellas, ni restos óseos de fauna, ni escorias (Tabla 2).

\begin{tabular}{|c|c|c|c|c|c|c|c|c|c|c|c|c|}
\hline & $\begin{array}{c}\text { Cerámica } \\
\text { ordinaria }\end{array}$ & $\begin{array}{c}\text { Cerámica } \\
\text { pintura/ } \\
\text { engobe }\end{array}$ & $\begin{array}{c}\text { Cerámica } \\
\text { vitrificada }\end{array}$ & Loza & Gres & $\begin{array}{c}\text { Porce } \\
\text { lana }\end{array}$ & $\begin{array}{c}\text { Vidrio } \\
\text { botella }\end{array}$ & $\begin{array}{c}\text { Vidrio } \\
\text { otros }\end{array}$ & $\begin{array}{c}\text { Óseo } \\
\text { fauna }\end{array}$ & Metal & Escoria & Otros \\
\hline Antiguyoc & 845 & 61 & 37 & 90 & 1 & 3 & 139 & 139 & 61 & 30 & 26 & 11 \\
\hline $\begin{array}{c}\text { Qda del } \\
\text { Maray 4 }\end{array}$ & 181 & 2 & 5 & 0 & 0 & 0 & 0 & 5 & 8 & 4 & 4 & 2 \\
\hline Ajedrez & 101 & 27 & 9 & 8 & 2 & 0 & 17 & 0 & 0 & 2 & 0 & 2 \\
\hline TOTAL & 1127 & 90 & 51 & 98 & 3 & 3 & 156 & 144 & 69 & 36 & 30 & 15 \\
\hline
\end{tabular}

Tabla 2. Cantidades de materiales recolectados en los sitios estudiados.

Para Antiguyoc la mayor parte de los materiales $(58,6 \%)$ consiste en fragmentos cerámicos ordinarios, correspondientes a vasijas, ollas y otros recipientes de probable uso cotidiano, con sus superficies alisadas; dichos materiales no presentan decoración y frecuentemente exhiben evidencias de exposición al fuego. En algunos casos hemos observado decoración en las asas, la que incluye modelados al pastillaje en zigzag (Figura 5 A, B y C), incisiones, incisión de surco rítmico, etc. En menor cantidad, hemos identificado fragmentos cerámicos que presentan pintura o engobe, mayormente de color rojo, que suele localizarse en la superficie externa. También hay un número importante de fragmentos con vitrificado en alguna o ambas superficies (Figura 6 E, F y G), que pueden o no presentar, además, decoración de motivos pintados. Los colores de los vitrificados son verdes y pueden relacionarse con la utilización de plomo. Pensamos que estos fragmentos no son de procedencia local, aunque 
sí pudieron ser manufacturados en regiones vecinas dado que son comparables con algunos que se confeccionaron allí hasta tiempos recientes. Las características de los materiales descritos presentan similitudes con otros sitios mineros del área analizados previamente, tales como Pan de Azúcar -con un fechado en un basurero de época colonial asociado a materiales comparables- y Timón Cruz (Pérez Pieroni, 2016).

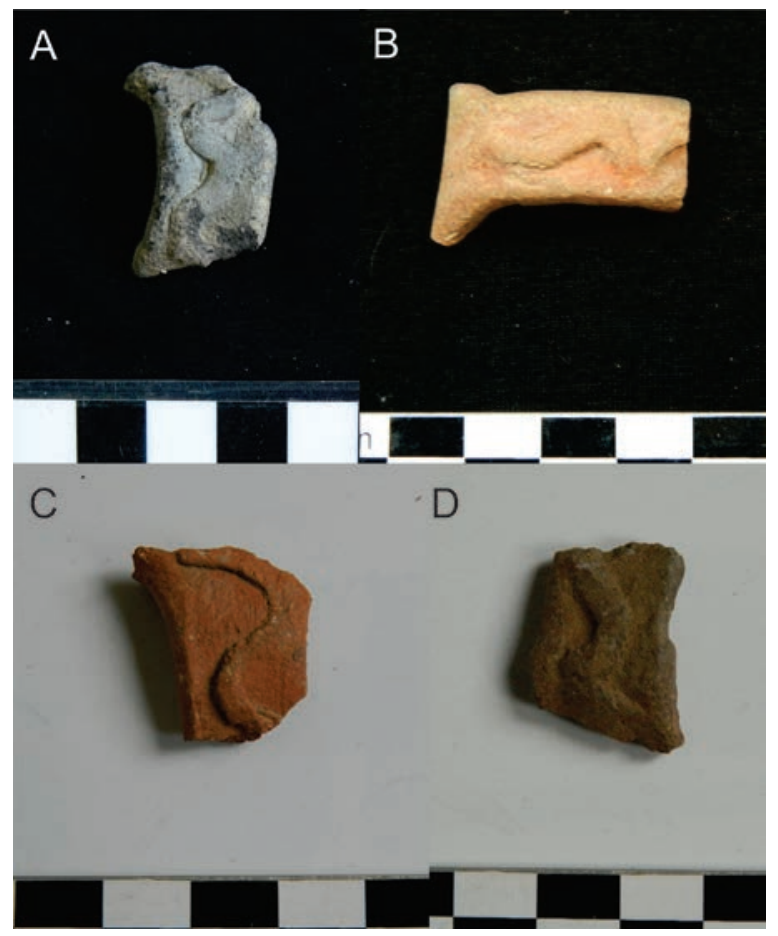

Figura 5. Asas con decoración al pastillaje en zigzag. A, B y C. Antiguyoc. D. Ajedrez.

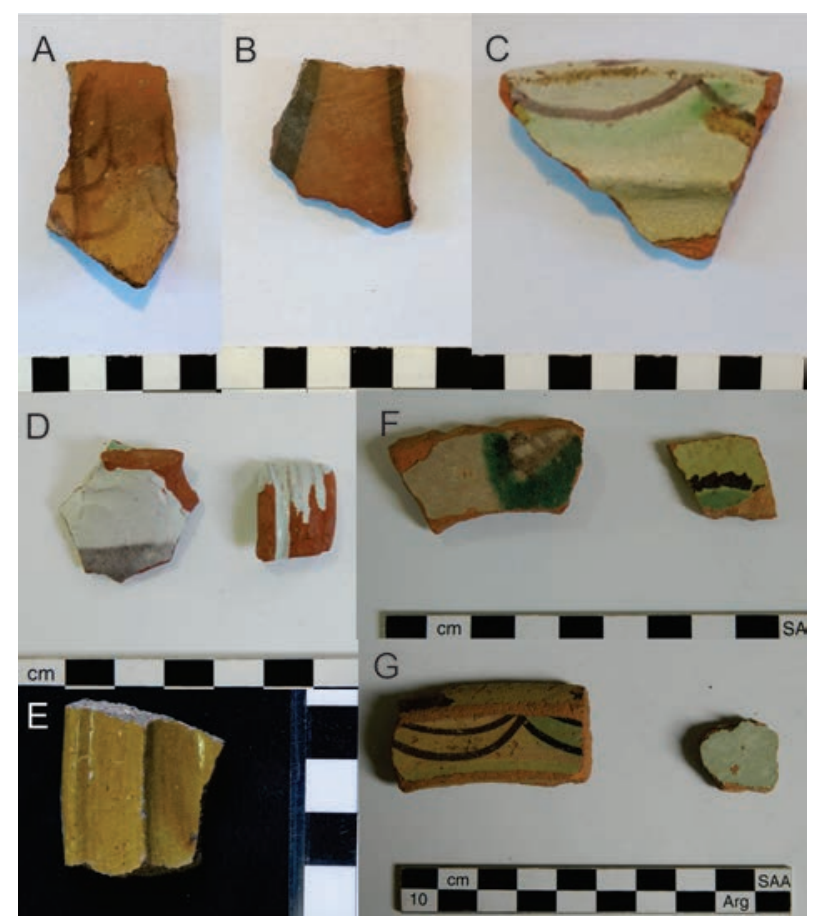

Figura 6. Fragmentos cerámicos decorados procedentes de los sitios estudiados. A, B y C. Ajedrez. D. Quebrada del Maray. E, Fy G. Antiguyoc. 
En Antiguyoc también hemos localizado un número importante de fragmentos correspondientes a lozas ( $n=90$ ) (Figura $7 \mathrm{~B}$ a F), que representa el 6,2\% del material recolectado. Corresponden mayormente a recipientes como platos y tazas -destinados al servicio y presentación de alimentos y bebidas-, aunque también hemos identificado bases de recipientes que pueden corresponder a albarelos. Pertenecen a lo que se ha denominado lozas Pearlware y Whiteware, en ocasiones presentan motivos decorativos pintados a mano o impresos que nos permiten ubicarlas cronológicamente durante todo el siglo XIX (Schavelzon, 2001).

Hay tres fragmentos de porcelana en Antiguyoc (Figura 7 A), todos procedentes de un mismo conjunto arquitectónico, próximo a la iglesia, y que no presentan motivos pintados. Hemos identificado un único fragmento de gres, que fue un material muy popular empleado para envases, tales como botellas de cerveza y ginebra durante el siglo XIX (Schavelzon, 2001).

Los materiales de vidrio son abundantes en Antiguyoc (19,2\%), aunque pensamos que fueron descartados en el sitio mayormente en épocas recientes, dado que la mitad de ellos corresponden a botellas de vidrio que presentan marcas de producción características de la fabricación con máquinas del siglo XX (Lindsay, 2017). No hemos identificado marcas de soplado ni de otras técnicas de producción más antiguas, aunque nos resta estudiar estos materiales con más detalle.

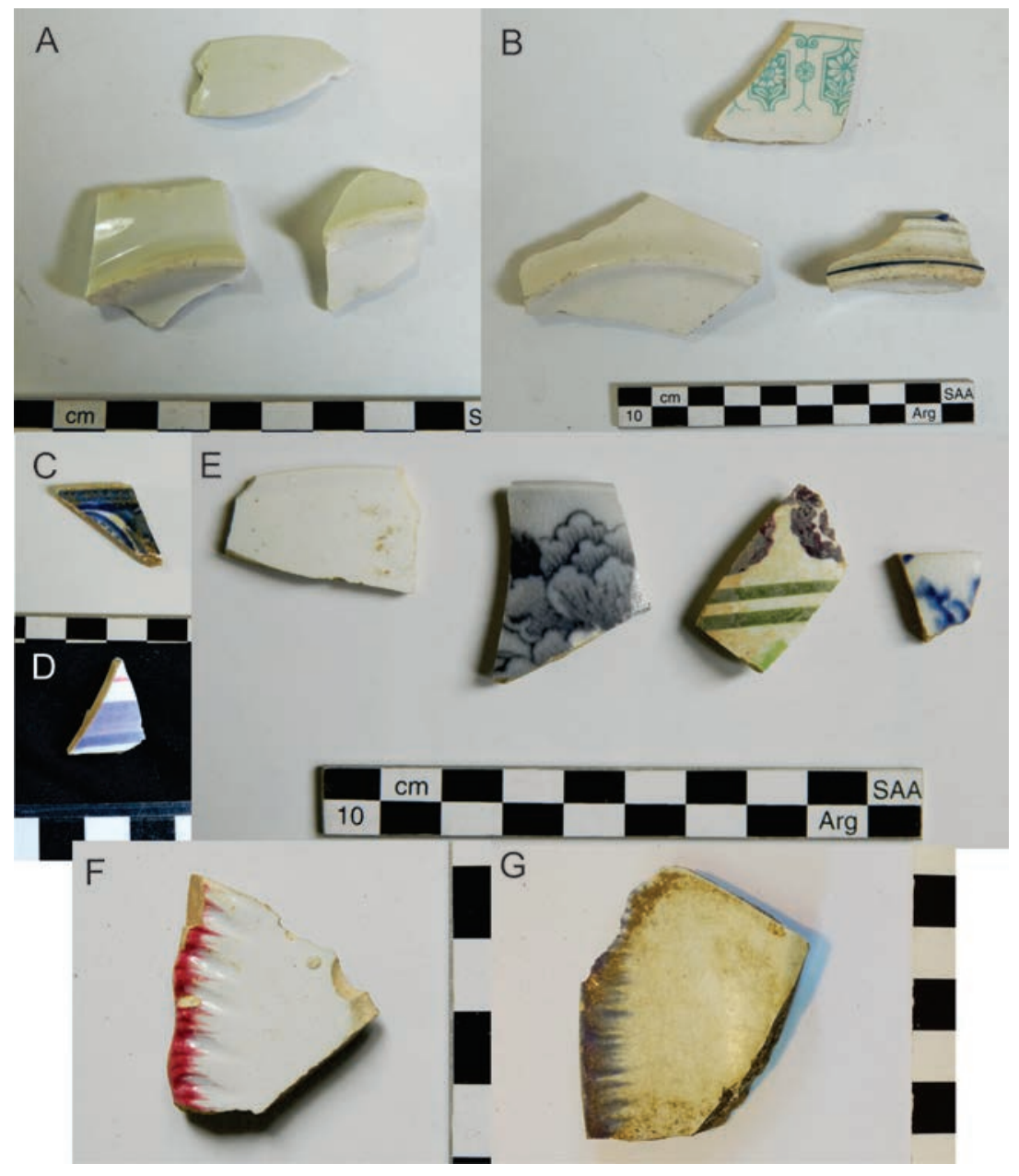

Figura 7. Fragmentos de porcelana y lozas recuperados en los sitios. A, B, C, D, E y F. Antiguyoc. G. Ajedrez. 
Los artefactos de metal son muy diversos, la mayoría de hierro (Figura 8). Están ausentes objetos que comúnmente se describen en otros sitios históricos, como los clavos. Se identificaron hojas de cuchillo, vainas de proyectil, latas, botones y otros objetos, todos de cronología indeterminada, exceptuando una moneda de diez centavos con fecha de 1943 recolectada en las inmediaciones de la Iglesia. También se han localizado veintiséis fragmentos de escoria, posiblemente relacionados a ciertas actividades minero-metalúrgicas que pudieron haber tenido lugar en el sitio, además de la explotación del oro local.

En el sitio Quebrada del Maray 4 son mayoritarios los fragmentos cerámicos ordinarios, alcanzando el $85,8 \%$ de los materiales recolectados allí. También habrían correspondido a recipientes de distintas morfologías que pudieron ser usados en actividades cotidianas. Se encuentran presentes los decorados plásticos sobre asas en forma de zigzag. Hay algunos fragmentos con vitrificados $(2,6 \%)$, también de colores verdes similares a los descritos para Antiguyoc y otros con vitrificados blancos (Figura 6 D). Estos materiales presentan semejanzas con los de ese sitio y con los de los otros sitios mineros del área que hemos mencionado anteriormente.

Sin embargo, en Quebrada del Maray 4 están ausentes las lozas, el gres y la porcelana. Los vidrios son muy escasos y no corresponderían a botellas. También hay objetos de metal, fragmentos de escoria y un trozo de mineral de cobre.

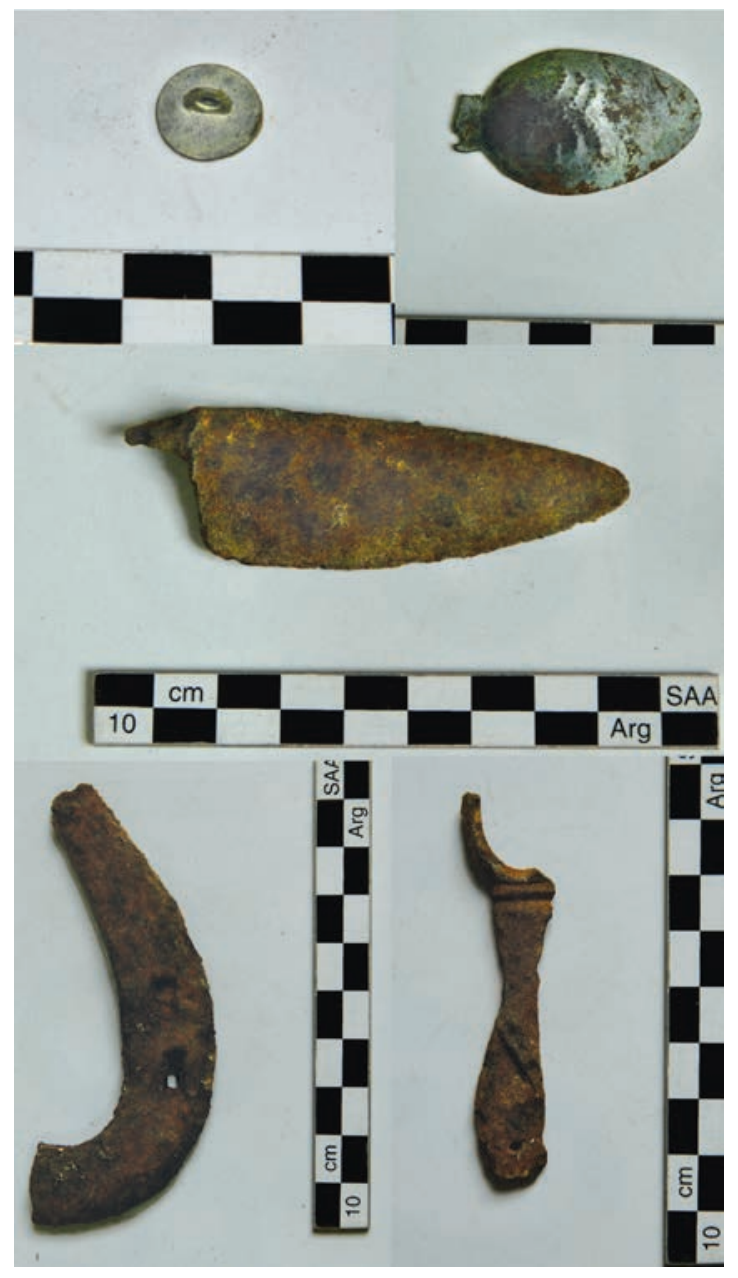

Figura 8. Algunos de los elementos de metal hallados en el sitio Antiguyoc. 
En Ajedrez también observamos una alta proporción de cerámica ordinaria $(60,1 \%)$. Sin embargo, aquí es destacable el porcentaje de fragmentos pintados y/o engobados (16,1\%) (Figura 6 A y B) en comparación con los dos sitios previos -donde el porcentaje es de tan solo 4,2 y $0,9 \%$ respectivamente. Estos fragmentos además suelen estar bien pulidos en una o ambas superficies y pueden asociarse a pastas muy compactas sin inclusiones visibles, comparables a nivel macroscópico con tipos cerámicos de momentos prehispánicos y coloniales, y que hemos relacionado con la modalidad productiva del norte de la puna, que se vincularía a los estilos Yavi-chicha (Pérez Pieroni, 2015). No obstante, serán necesarios estudios petrográficos que nos permitan comparar las composiciones litológicas y mineralógicas de los fragmentos con aquellos analizados previamente. Asimismo, hemos registrado también un fragmento con un motivo pintado (Figura $6 \mathrm{~A}$ ) comparable a los presentes en una botella procedente del Pukara de Rinconada y para la cual se postula una cronología colonial (Pérez Pieroni, 2016). Por otro lado, aunque aquí también los fragmentos con vitrificados en sus superficies son escasos (Figura 6 C), se observa que la proporción es levemente mayor que en los otros sitios $(5,4 \%$ contra 2,5\%). Finalmente, hemos registrado un asa con decoración en zigzag al pastillaje (Figura $5 \mathrm{D}$ ).

Los fragmentos de loza recuperados en Ajedrez son escasos $(n=8)$ y corresponden a los tipos Pearlware y Whiteware (Figura 7 G). Además, se hallaron dos fragmentos de recipientes de gres. Los fragmentos de vidrio corresponden en su totalidad a botellas, cuyas características nos permiten suponer que son recientes, dado que no se observan marcas de soplado ni otros atributos tecnológicos antiguos.

Considerando los cambios que hemos registrado hasta la fecha en la cerámica regional (Angiorama y Pérez Pieroni, 2012; Pérez Pieroni, 2014, 2016), pensamos que la presencia en este sitio de una mayor proporción de fragmentos engobados y pulidos con pastas compactas y de fragmentos pintados y vitrificados podrían estar indicando una ocupación más antigua que las de Antiguyoc y Quebrada del Maray 4.

Por otro lado, es destacable que en los tres sitios aquí abordados registramos un tipo cerámico que hemos identificado en trabajos previos asociado exclusivamente a lugares relacionados con actividades minero-metalúrgicas, como Pan de Azúcar, Mina Pan de Azúcar y el Pukara de Rinconada. Se trata de recipientes con asas con decoraciones en zigzag que mayormente se realizaron al pastillaje, pero que también pueden estar incisas. Este tipo de decoración también ha sido localizado en otros sitios mineros puneños, como Incahuasi en Catamarca (Lema, 2012), y en el sur de Bolivia (Cruz, 2016). Como Cruz (2016), planteamos como hipótesis que podría tratarse de un tipo cerámico vinculado a espacios mineros o a personas relacionadas con estas actividades, y que surge en época colonial, dado que no hemos registrado este tipo de decoración en momentos prehispánicos.

Salvo los fragmentos de escoria, los materiales descritos hasta el momento estarían relacionados con las actividades domésticas de las personas que vivieron en los tres sitios aquí abordados, no observándose hasta el momento implementos que puedan vincularse con las actividades productivas. Los recipientes cerámicos pudieron ser usados en actividades cotidianas tales como la preparación, el servicio y el consumo de alimentos, y probablemente correspondan a cerámicas producidas a nivel local o regional, dado que sus características tecnológicas no difieren de aquellas descritas en nuestros trabajos previos en el 
18. Por ejemplo, de Rinconada se decía que "empezó a fundarse cuando con las labores de las vetas reales ocurrió gente de cada parroquia que después sucesivamente se han descubierto muchos veneros, aventaderos y lavaderos en la circunferencia de este asiento cuyos motivos aumentaron y multiplicaron la población" (AGN, Sala IX, Leg. 34-4-6, fs. 10V.-11. Año 1803). área. El uso de estos recipientes cerámicos ordinarios, similares a los de otros sitios de la cuenca de Pozuelos y a regiones vecinas, puede estar dando cuenta de grupos familiares locales empleando los mismos implementos y materiales que en épocas previas. Como hemos señalado en otras oportunidades, los indígenas de la época colonial continuaron usando básicamente los conjuntos cerámicos de sus ancestros en nuestra región de estudio. Sin embargo, la introducción de cerámicas con vitrificados, y posteriormente de lozas, podría estar vinculada a la presencia de europeos o criollos en los asentamientos estudiados, o a un interés en reproducir las prácticas de almacenamiento y servicio de alimentos propias de Europa.

\section{Combinando ambos registros}

Si combinamos la información histórica y arqueológica disponible hasta el momento, podemos realizar algunas consideraciones, hipotéticas aún, acerca de los tres asentamientos analizados en este trabajo.

En primer lugar, proponemos que los sitios arqueológicos de Ajedrez y Antiguyoc conforman los asientos que la documentación refiere como mineral de Ajedrez y la sede de Viceparroquia de Antiguyoc. Con el tiempo Antiguyoc asumió características más "urbanas", la densidad y disposición de sus construcciones sugiere que allí residió la mayor parte de las familias registradas en los padrones tardocoloniales mencionados.

El pueblo de Antiguyoc era visitado por un cura periódicamente, en él se realizaban bautismos y seguramente también casamientos -aunque no se conserven registros de estos últimos. De todas maneras, era también un asiento minero, por lo que al igual que otros sitios contemporáneos de la puna, como Rinconada, las áreas de extracción aurífera se encontraban íntimamente vinculadas a las viviendas del poblado. ${ }^{18}$ Este lugar perduró como Viceparroquia colonial desde su creación en 1773 hasta el final de ese período. Eso lo habría convertido en un "mojón" de origen hispánico -al igual que el resto de las Parroquias y Viceparroquias- donde los habitantes locales generaron un vínculo mediante las prácticas de la fe católica. La diversidad de materiales asignables a diferentes épocas hallados en superficie, principalmente en el sector donde se encuentra la iglesia, habla de la permanente concurrencia de gente desde el siglo XVIII hasta la actualidad. Por lo tanto, lejos de disolverse tal relación perduró con los años y habría motivado la construcción del cementerio y las remodelaciones y mantenimiento de su iglesia. Ambos, templo y camposanto, aún atraen la asistencia de personas.

El sitio que denominamos Quebrada del Maray 4 reúne en sus aspectos materiales las características necesarias para haber funcionado, en su núcleo central, como una estancia. Ciertos elementos de las descripciones plasmadas en el testamento de Dávalos, como el patio que habría funcionado como cancha de matanza y la cantidad de recintos que componen el sector principal, encuentran coincidencia con lo que hemos registrado durante nuestros relevamientos en el sitio. Algunas variaciones detectadas, como la subdivisión de la cancha, corresponderían a modificaciones llevadas a cabo con posterioridad a 1776, quizás bajo la administración de propietarios que sucedieron a Dávalos, como F. de Azebey. Al mismo tiempo, este espacio tan característico por sus dimensiones y la altura de sus muros está ausente en el cercano sitio de Antiguyoc. Por ello planteamos que Quebrada del Maray 4 correspondería al lugar de residencia de Dávalos y su familia, mencionado en su testamento. Además de la cancha de matanza de ganado allí se realizaban trabajos de minería, evidenciado por 
un sector con desmontes y trincheras asociadas a las viviendas dispuestas de manera lineal. El asentamiento de Antiguyoc se encontraba dentro de la propiedad de la hacienda pero, de acuerdo con la documentación, sus habitantes no habrían pagado arriendos por su condición de asiento de mineral (Gil Montero 2004; Becerra 2014a, 2014b). ${ }^{19}$

En suma, lo que las fuentes documentales y la bibliografía analizada señalan como "Antiguyoc" habría sido una localidad, paraje o "partido" 20 que comprendió, por lo menos durante momentos tardocoloniales, dos asentamientos hispánicos principales: el sitio homónimo y Quebrada del Maray 4. El hecho de que los nombres de los lugares que aparecen en los censos o revisitas hacen mención a zonas más amplias que un poblado ya había sido advertido por Gil Montero (2004). A su planteo sobre el patrón de asentamiento en la Puna durante momentos coloniales tardíos agregamos que asientos mineros que no eran cabecera de curato, como Antiguyoc, también terminaron adquiriendo una fisonomía de pueblo, con una estructuración "urbana" en torno a una iglesia.

Por último, las construcciones y elementos muebles de la quebrada de Ajedrez exhiben las diferentes épocas por las que atravesó el lugar, desde los materiales arqueológicos más tempranos -los cuales refuerzan la idea de que este asentamiento se trata del mineral de Ajedrez mencionado en las fuentes de comienzos del siglo XVII-, pasando por su etapa de posible Viceparroquia en el siglo XVIII, hasta la instalación de la Compañía Aurífera Jujeña a finales del siglo XIX. En este sentido, las reiteradas reocupaciones de Ajedrez durante prácticamente tres centurias se traducen en la trama desordenada que hoy se observa en sus ruinas, destacando la gran densidad y diversidad de construcciones y materiales registrados. En uno de los casos, la identificación de viviendas excavadas en las barrancas del río nos remiten a los llamados guasis de asientos mineros, como San Antonio del Nuevo Mundo, viviendas precarias, de rápida construcción y generalmente ubicadas cerca de las minas (Gil Montero, 2015). De todas maneras permanece el interrogante sobre la temporalidad de estas construcciones: ¿corresponden a un primer momento de rápido asentamiento y exploración, o se trata de refugios de mineros que requerían de espacios para vivir cuando la explotación estaba en su mayor auge? Por otro lado, en las antípodas de estas expeditivas y pequeñas viviendas se encuentra el amplio complejo constructivo con extenso patio y vanos en arco de medio punto al que hicimos referencia arriba. Sus características permiten hipotetizar que su construcción estuvo vinculada a la instalación de la compañía minera la Aurífera Jujeña.

Cuando Brackebusch describió Ajedrez a finales del siglo XIX se preguntaba en su relato: “¿Qué fue lo que creaba esta vida? Nada más que la furia de buscar el oro. Acabándose éste, se acabó también la población” ([1883] 1981: 44). En este sentido, la aseveración de este autor es válida para los tres sitios presentados en este trabajo. Las evidencias arqueológicas que hemos registrado son principalmente consecuencia de oleadas de antiguos mineros llegados a este sector de la puna jujeña bajo el impulso de esa "furia de buscar oro".

\section{Agradecimientos}

Agradecemos especialmente a cada uno de los miembros del equipo que participaron en las tareas de campo realizadas en el área de estudio, y a Cecilia Castellanos por habernos facilitado uno de los documentos históricos que necesitábamos. Las investigaciones fueron financiadas gracias a subsidios PICT (FONCyT), PIP (CONICET) y PIUNT (Universidad Nacional de Tucumán).
19. "En los inmediatos asientos de minerales de Santa Catalina, Antiguyo, Portugalete y otros" no exigían "los dueños de aquellos terrenos absolutamente reconocimiento $\mathrm{ni}$ obligaciones a los mineros y abastecedores" (AGN, Sala IX, Leg. 23-5-6, Exp. 310 , fs. 4V. y 84. Año 1803,). En estos testimonios mencionaban a las estancias de Santa Catalina y Antiguyoc como minerales cuyos propietarios, Pedro Pablo Aramayo y Francisco Acebey y herederos, respectivamente, no cobraban "el derecho de reconocimiento o pensión antes bien al contrario sólo han satisfecho el arriendo aquellos indios que tienen ovejas, burros, o carneros del país" (AGN, Sala IX, Leg. 34-4-6, f. 14v. Año 1803).

20. A pesar de que ya había sido declarado Viceparroquia, figura con esa denominación en el censo de 1778/79 (Rojas, 1913). 


\section{Fuentes documentales citadas}

》Archivo y Biblioteca Históricos de Salta (ABHS).

Carpeta 63, Cuaderno 94. Año 1825, Documentaciones Varias. Registro de Minas.

» Archivo Colección Ricardo Rojas, Jujuy (ACRR).

Caja XVIII.

» Archivo General de la Nación, Argentina (AGN).

Sala IX, Leg. 33-8-5. Año 1793, Sumario contra subdelegado de la puna, J. Villegas.

Sala IX, Leg. 30-5-2. Año 1792, Pulperías en los pueblos de la Puna.

Sala IX, Leg. 23-5-6. Año 1803, Rinconada: procedimientos de A. Barcena con los mineros del pueblo.

Sala IX, Leg. 34-4-6. Año 1803, Juicio cobro de arriendos en Rinconada.

Sala XIII, 17-2-1. Años 1785-1792, Padrones de Salta.

" Archivo de Tribunales de Jujuy, Argentina (ATJ).

Carpeta 26, Leg. 794. Año 1706, Expedientes varios

Carpeta 50, Leg. 1653. Año 1776, Testamentaria de Dávalos en Antiguyoc.

Carpeta 51, Leg. 168o. Año 1777, Comisión por pago de deudas en Rinconada. 


\section{Q Bibliografía citada}

» Albeck, M. E. y S. Palomeque (2009). Ocupación española de las tierras indígenas de la puna y "raya del Tucumán" durante el temprano período colonial. Memoria Americana. Cuadernos de Etnohistoria 17 (2): 173-212.

» Alonso, R. (2010). Historia de la minería de Salta y Jujuy. Siglos XV-XX. Salta, Mundo Gráfico Salta Editorial.

» Alonso, R. N., T. Ruiz, A. Quiroga y C. González Barry (2013). “Protagonistas de la minería de oro aluvional en la puna jujeña en el siglo XIX". Actas del $11^{\circ}$ Congreso de Mineralogía y Metalogenia: 159-164. San Juan, Facultad de Ciencias Exactas, Físicas y Naturales, Universidad Nacional de San Juan.

" Angiorama, C. y M. F. Becerra (2012). El oro de la Puna: lavaderos, socavones y mineros en el período colonial. Arqueología de la minería aurífera del extremo norte de la Puna de Jujuy (Argentina). Vestigios, Revista Latino-Americana de Arqueología Histórica 6 (1): 49-80.

" Angiorama, C. y M. J. Pérez Pieroni (2012). Primeros estudios sobre manufactura cerámica de contextos coloniales del sur de Pozuelos (Puna de Jujuy, Argentina). Revista de Arqueología Histórica Argentina y Latinoamericana 6: 95-126.

"Becerra, M. F. (2012). Cruces entre la Arqueología y la Historia. Hornos, socavones y registros: las prácticas minero-metalúrgicas coloniales en la Puna de Jujuy a través del complejo Fundiciones 1 (Rinconada, Jujuy, Argentina). Población y Sociedad 19: 5-39.

»Becerra, M. F. (2014a). "Para labrar y poblar" Prácticas minero-metalúrgicas en la Puna de Jujuy durante el período colonial (siglos XVII y XVIII). Tesis Doctoral inédita. Buenos Aires, Facultad de Filosofía y Letras, Universidad de Buenos Aires.

"Becerra, M. F. (2014b). Para que "creciera el pueblo como Potosi”: la minería en la puna de Jujuy durante el período colonial. Estudios Atacameños 48: 55-70.

»Brackebusch, L. ([1883] 1981). Por los Caminos del Norte. Tucumán, Colegio de Graduados en Ciencias Geológicas de Tucumán.

»Cabanettes, C. y L. Amans (1891). Memoria de la expedición por las regiones auríferas del norte de la provincia de Jujuí emprendida por la comisión nombrada por el Superior Gobierno de la Nación en abril de 1891. Buenos Aires, Imprenta y Librería de Mayo.

" Cruz, P. (2016). Imágenes en pugna. Reflexiones en torno a las producciones visuales indígenas en el ámbito de la minería colonial. Boletín del Museo chileno de Arte Precolombino 21 (1): 95-113.

》Estruch, D. (2013). “Administración de la justicia y conflictos jurisdiccionales en el Jujuy colonial (siglos XVI y XVII)” en Lorandi, A. M. (comp.), El ocaso del imperio. Sociedad y cultura en el centro-sur andino: 125-152. Buenos Aires, Antropofagia.

»Estruch, D., L. Rodríguez y M. F. Becerra (2011). Jurisdicciones mineras en tensión. El impacto de la minería en el Valle de Yocavil y la Puna Jujeña durante el período colonial. Revista Histórica XXXV (2): 69-100.

" Freixas Camps, P. (1975). Significación de la arquitectura prerrománica. Revista de Girona 73: $12-15$.

" Gil Montero, R. (2004). Caravaneros y transhumantes en los Andes Meridionales. Población y familia indígena en la Puna de Jujuy 1770-1870. Lima, Instituto de Estudios Peruanos. 
" Gil Montero, R. (2015). Ciudades efímeras. El ciclo minero de la plata en Lípez (Bolivia), siglos XVI-XIX. La Paz, IFEA/ Plural.

» Jutoran, A. (1958). Manifestaciones auríferas en los departamentos de Cochinoca y Rinconada (Provincia de Jujuy). Informes inéditos de la Dirección Nacional de Geología y Minería. Carpeta № 398 . Biblioteca SEGEMAR.

"Lema, C. (2012). El Mineral de Incahuasi. Oro e historia en la encrucijada colonial. Tesis Doctoral inédita. Catamarca, Facultad de Humanidades, Universidad Nacional de Catamarca.

»Lindsay, B. (2017). Historic Glass Bottle Identification \& Information Website. Disponible en Internet: sha.org/bottle/index.ht. Consultado el: 1 de noviembre de 2017.

"López Mullor, A. (2010). “La construcción de un método de intervención en el patrimonio arqueológico edificado" en Morales, C. M. y de Vega García, E. (coords.), Arqueología aplicada al estudio e interpretación de edificios históricos. Últimas tendencias metodológicas: 65-102. España, Ministerio de Cultura.

» Martín-Rincón, J. G. (2001). Pisos coloniales de Panamá La Vieja: una manera de reforzar el status. Arqueología De Panamá La Vieja 1: 225-238.

"Novarese, V. (1893). Los yacimientos auríferos de la Puna de Jujuy. Anales de la Sociedad Científica Argentina XXXV (primer semestre): 89-117.

»Pérez Pieroni, M. J. (2014). Primera caracterización petrográfica de pastas cerámicas prehispánicas tardías y coloniales de la cuenca sur de la Laguna de Pozuelos (Puna de Jujuy, Argentina). Arqueología 20 (1): 31-46.

"Pérez Pieroni, M. J. (2015). Prácticas productivas y tradiciones tecnológicas: la manufactura cerámica prehispánica tardía y colonial en la cuenca sur de Pozuelos y el área de Santa Catalina, Puna de Jujuy, Argentina. Relaciones de la Sociedad Argentina de Antropología XL (1): 13-44.

»Pérez Pieroni, M. J. (2016). Tecnología cerámica de época colonial en la cuenca sur de Pozuelos y el área de Santa Catalina, puna de Jujuy, Argentina. Revista de Arqueología Histórica Argentina y Latinoamericana. En prensa.

» Rojas, R. (1913). Archivo Capitular de Jujuy, Tomo I. Buenos Aires, Imprenta de Coni Hermanos.

» Schavelzon, D. (2001). Catálogo de cerámicas históricas de Buenos Aires (s. XVI - XX). [Formato $C D$ ]. Buenos Aires, Fundación para la Investigación del Arte Argentino (FIAAR).

"Schilman, M. y D. Reisner (2011). "Pircando con piedras en Susques y Rinconada. Usos y funciones, conocimientos y saberes a través de la experiencia" en Tomasi, J. y C. Rivet (coords.), Puna y arquitectura. Las formas locales de la construcción: 57-70. Buenos Aires, CEDODAL.

"Sgrosso, P. (1943). Contribución al conocimiento de la minería y geología del NOA. Boletín 53. Buenos Aires, Ministerio de Agricultura de la Nación.

"Sica, G. (2006). Del Pukara al Pueblo de indios. El proceso de construcción de la sociedad indígena colonial en Jujuy, Argentina. Siglo XVII. Tesis Doctoral. Sevilla, Facultad de Geografía e Historia, Universidad de Sevilla.

»Sica, G. y M. Ulloa (2007). “Jujuy en la Colonia. De la Fundación de la ciudad a la crisis del orden colonial” en Teruel, A. y M. Lagos (dirs.), Jujuy en la historia. De la colonia al siglo $X X:$ 41-84. Jujuy, Argentina. Editorial de la UNJu. (2º edición).

»Ulloa, M. (2005). Comerciantes, pulperos, hacendados y buscadores de oro. Españoles en la Puna de Jujuy a fines del Siglo XVIII. Actas del VI Congreso Internacional de Etnohistoria. Buenos Aires, Argentina.

»Vergara, M. A. 1942. Estudios sobre historia eclesiástica de Jujuy. San Miguel de Tucumán, Instituto de Historia, Lingüística y Folklore, Universidad Nacional de Tucumán. 